\title{
Orchioepididymitis Tuberculosis in Limited Setting: A Case Report and Brief Literature Review
}

\author{
Heru Sutanto Koerniawan ${ }^{1 *}$, I. Wayan Yudiana ${ }^{2}$, I. Made Bayu Indratama ${ }^{3}$, Novitasari Novitasari ${ }^{4}$, Yofatifa Ramandey ${ }^{5}$ \\ ${ }^{1}$ Department of Surgery, Pelita Harapan University, Siloam General Hospital, Tangerang, Indonesia; ${ }^{2}$ Department of Surgery, \\ Division of Urology, Udayana University, Sanglah General Hospital, Denpasar, Indonesia; ${ }^{3}$ Department of Internal Medicine, \\ Oksibil District General Hospital, Pegunungan Bintang Regency, Indonesia; ${ }^{4}$ Pathology Laboratory, Wangaya City General \\ Hospital, Denpasar, Indonesia; ${ }^{5}$ Emergency Unit, Oksibil District General Hospital, Pegunungan Bintang Regency, Indonesia
}

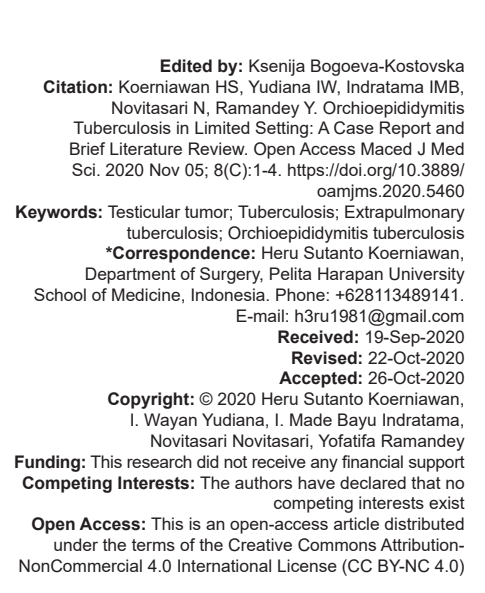

\section{Introduction}

To date, tuberculosis (TB) remains a major global health concern. The disease appears to be one of the most important infections after AIDS [1], [2]. According to the World Health Organization report 2013, there were 8.6 million new TB cases in 2012 and 1.3 million TB deaths (just under 1.0 million among HIV-negative people and 0.3 million HIV-associated TB death) [1]. It is of vital importance the fact that the incidence of TB increases not only in developing and poor countries but also in economically strong and stable countries, including the USA [2]. The decline of the epidemiological boom of TB during the last two decades is true for pulmonary TB but also appears true to be almost constant incidence of TB affecting other organs than lungs [2]. The most common etiology of chronic specific infections of the genital system is classical form TB that is present in $38-40 \%$ of all cases [2]. While it is uncommon, genitourinary TB is considered the second most common form among the extrapulmonary TB, being only behind the lymph nodes that are the most common site of extrapulmonary TB [3]. Drudi et al. reported that every 6 years, there is an incidence 48/35,000 of TB epididymitis [4]. Chattopadhyay et al. also reported that genitourinary TB represents $20-73 \%$ of all forms of extrapulmonary TB [5].

TB of the genital system may be present during primary infection but also may develop late after a long latent period. It has been shown that TB of the genital system may be present 20-30 years after primary localization [2]. The source of infection might be an existing primary focus in the lungs or lymph node and rarely from bones, bowels or could be endogenous reinfection or exogenous superinfection [2], [6], [7].

Extrapulmonary TB still presents a diagnostic and therapeutic challenge [8], [9], [10]. The patient usually presents late, especially due to the poor symptoms and latency between the first infection and the clinical manifestations that can occur up to 30 years after exposed to the bacteria [9]. Clinically, TB of the scrotum often cannot be distinguished from lesions such as tumor and infarction, especially in apparently healthy patients with no other clinical symptoms or signs [8], [9], [10], [11]. The diagnostic dilemma often results to inappropriate surgical procedures for a potentially curable medical illness. 
In this article, we report one adult male patient with a clinical diagnosis of testicular tumor who was treated in Oksibil District General Hospital, Pegunungan Bintang, Papua, with post-operative diagnosis of orchioepididymitis TB without any trace of TB elsewhere in the body, followed by a literature review of the best diagnosis, treatment, and follow-up of the case. The importance of the case is unilateral involvement of epididymis and testis mimicking testicular tumor.

\section{Case Report}

A 30-year-old male presented to the surgical clinic in our district general hospital with a painless swelling of the right testis for 6 months. He also complained of recurrent low-grade fever for the past 3 months, not associated with chills or rigor. No swelling and pain at the inguinal region. He also did not have any voiding difficulties. He was never diagnosed with TB or trauma in the past. He also denied any family history of TB. The general examination was unremarkable. Upon examination, there was boggy swelling of the right spermatic cord as well as an $8 \mathrm{~cm} \times 6 \mathrm{~cm}$ hard and nontender swelling in the right testis with a smooth surface, while the left hemiscrotal were clinically normal. The ESR was $45 \mathrm{~mm}$ in $1 \mathrm{~h}$ and total leukocyte count was $5700 / \mathrm{mm}^{3}$ with 25 lymphocytes and 70 polymorphs. The urine analysis showed 1-2 red blood cells. There were no radiology facilities at the moment, neither the referral system as we are in a remote area. Clinical diagnosis of testicular and epididymis tumor was made and we opted for a right inguinal orchiectomy due to the possibility of malignant neoplasm (Figure 1). The sample was sent to the Pathology Laboratory at Denpasar, Bali, Indonesia.

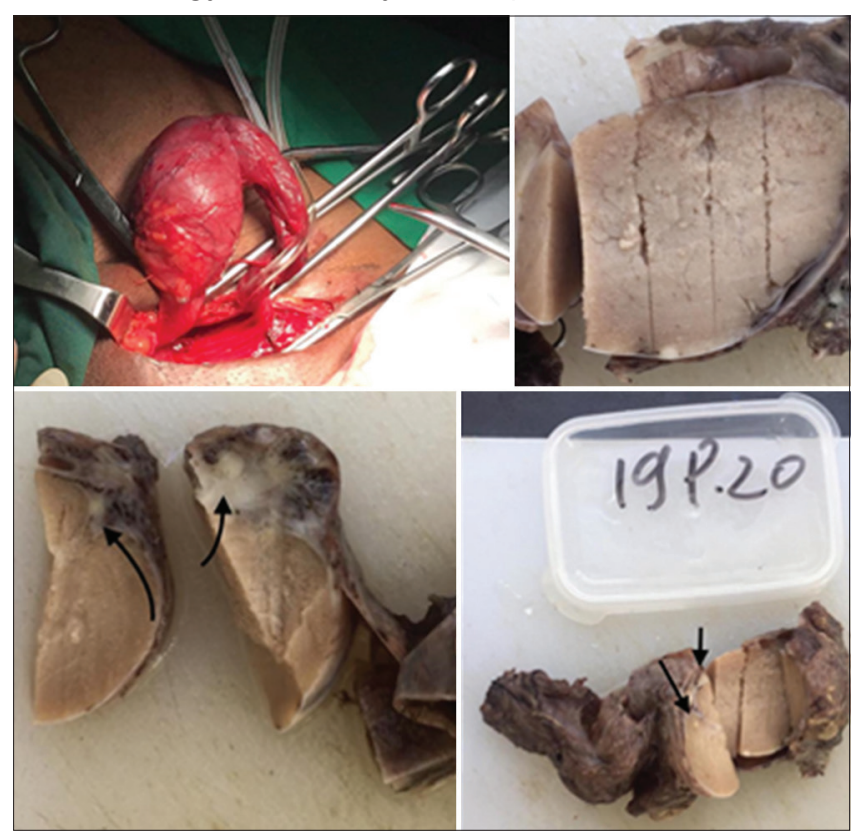

Figure 1: Right inguinal orchiectomy (upper left) and the cut section of gross specimen (upper right, lower left, and lower right)
Cut section of the gross specimen showed some part of testicular parenchyma filled with yellowish caseated spot (Figure 1). Histopathology examination revealed a granulomatous lesion, consistent with TB orchitis. Testicular parenchyma was filled with aggregates of epithelioid histiocytes, lymphocytes, and multinucleated giant cells that form granulomatous structure surrounded by solid sparse of lymphocytes and plasma cells (Figure 2). There were granulomatous focuses between seminiferous tubules and epididymis tubules structure (Figure 3).

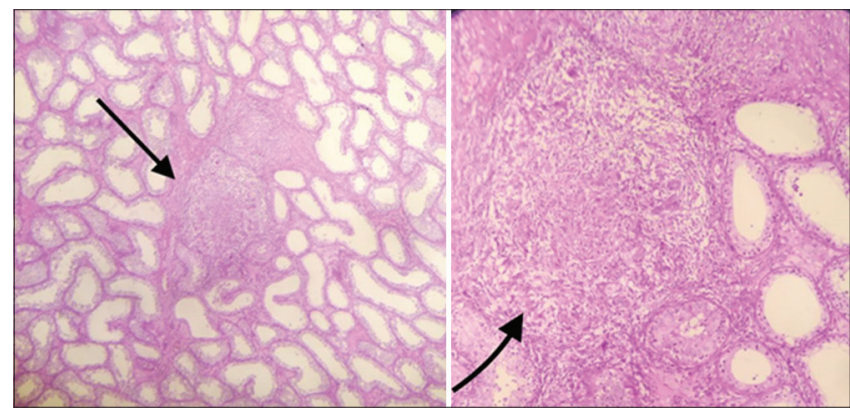

Figure 2: Granulomatous structure in the testicular parenchyma

The patient then was referred to the internal medicine and initiated immediately with rifampicin, isoniazid, pyrazinamide, and ethambutol for 2 months and followed by 4 months of rifampin and isoniazid regiment.

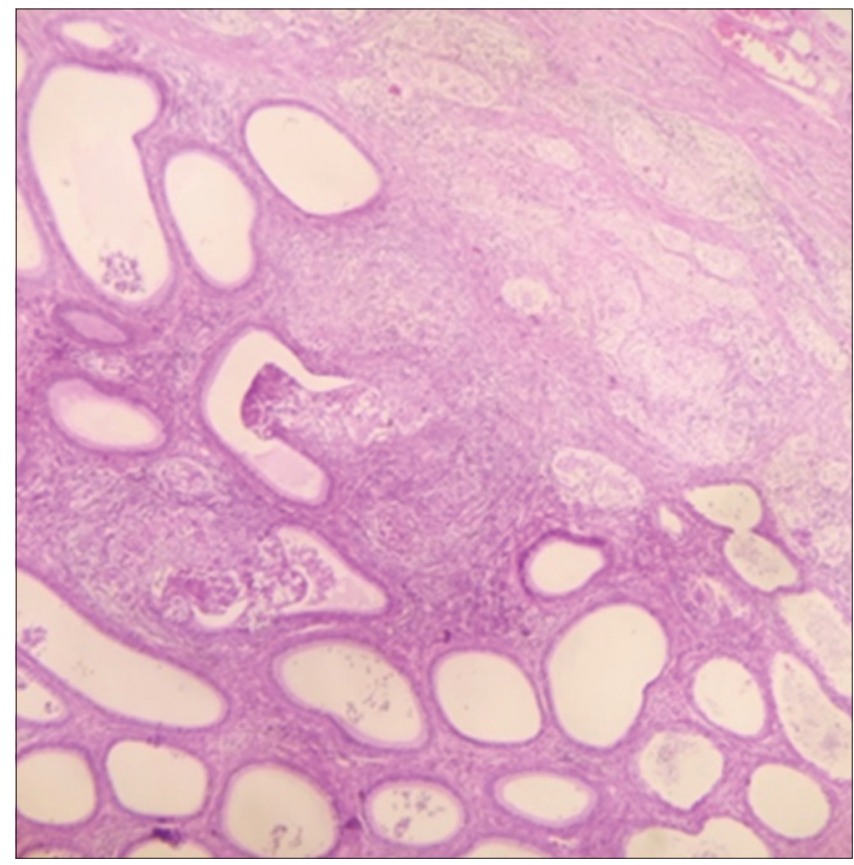

Figure 3: Granulomatous structure between seminiferous tubules and epididymis tubules together with normal tissue of epididymis

\section{Discussion}

Genitourinary TB is uncommon presentation of TB and comprises 8-15\% of extrapulmonary TB, which is the second most common site of extrapulmonary TB [9]. Up to $28 \%$ of the disease have isolated genital involvement [11], [12]. Genitourinary TB affects male 
population predominantly in the most active age between 20 and 40 years [2]. Our patient age is 30 years old. The genital involvement can be found in extensive pulmonary tubercular disease or presents as a primary isolated genital lesion. The spread of Mycobacterium tuberculosis to the scrotal components is typically hematogenous, usually from a primary lung or kidney site. It can also be disseminated through retrograde extension from the prostate and seminal vesicle to the epididymis and the testicles [13]. Orchitis TB occurs as results of contagious extension from the epididymis [7]. Tubercular epididymitis usually arises at the epididymal tail, the area with the largest blood supply and also the first portion affected by urinary reflux [13], [14]. From here, if the infection goes unchecked, the disease could extend to the testis and this reflects a later stage of the disease process [7]. The isolated Orchitis TB resulting from hematogenous spread without epididymal involvement is rare [7], [13]. In our case, he had no identifiable primary lung or other extra scrotal focus. Our case also showed the usual course of the disease involving epididymis and then spread to the testis.

Although it is quite difficult and may occur many years after the primary infection, history and physical examination may help distinguish the presence of TB from other sources genital pathology. Initial presentation could include testicular pain that usually subsidized after 2-4 weeks, palpable mass, swelling without any discharging sinus, scrotal involvement, and in more advanced cases fistulas and infertility [1], [3], [16]. Patients with orchioepididymitis TB have milder symptoms than pyogenic orchioepididymitis, so they will seek the physician later and most of the time in the latter stage of disease as our patient did as well. There is no evidence of more frequent affection of the right or left side, but Tzetkov reported unilateral involvement in $68.12 \%$ of cases [2]. In our case, the clinical finding is unilateral right painless nodule and recurrent fever. The definitive diagnosis of orchioepididymitis TB is by isolating the bacillus from the orchioepididymitis tissue by finding the epithelioid granulomas and acid-fast bacilli on Ziehl-Neelsen staining in the tissue obtained from the testis and epididymis. Another modality is a polymerase chain reaction, a fast molecular test that can also provide a diagnosis with high sensitivity and specificity rates [9], [17]. In our case, we rely on the post-operative histopathology finding.

The treatment of all forms of TB involves a combination of medications aimed at avoiding bacillary resistance and must be started immediately after pathological or microbiological diagnosis or even empirically if there is supporting strong clinical, radiological as well as laboratory data leads to the suspicious of TB [16]. Non-surgical management is the first line of non-complicated orchioepididymitis TB. If there are complications or advance cases such as abscesses, cutaneous fistulas, or extensive involvement of the epididymis and testis and when pharmacological treatment fails, then surgery may be opted. Kundu et al. reported a case of Orchitis TB diagnosed by fine-needle aspiration cytology; the lesion regressed with anti-TB medication regiment [11], [18]. In our case, due to the geographical constraints as well as limited diagnostic tools in our hospital, as well as the risk of neoplasia, we opted for surgery. And then, postsurgery, he was tested for sputum for acid-fast bacilli sputum smear examination and the result was negative. Afterward, he was treated with combination therapy of isoniazid, rifampin, ethambutol, and pyrazinamide for 2 months and then followed by rifampin and isoniazid for 4 months.

\section{Conclusion}

The present case might be considered as a rare unilateral orchioepididymitis TB. Sometimes, it is very hard to differentiated orchioepididymitis TB from testicular malignancy because genital TB has no pathognomonic signs. In a limited setting, we really have to be vigilant and use the best available diagnostic tools to find the cause of the scrotal lump and to make a decision for the best available treatment of extrapulmonary TB, particularly genitourinary TB.

In summary, we want to convey a message that though genitourinary TB, particularly orchioepididymitis $\mathrm{TB}$, is a rare condition but should be considered when assessing the focal lesion of the testes, especially in the endemic area of TB and or those with risk factor such as HIV and other immunodeficiency condition especially if the infection of the male genital organ does not improve by antibiotic treatment. The treatment of all forms of TB involves a combination of medications aimed at avoiding bacillary resistance and must be started immediately after pathological or microbiological diagnosis or even empirically if there is supporting strong clinical, radiological as well as laboratory data leads to the suspicious of TB.

\section{References}

1. Yonguc T, Bozkurt IH. Male genital tuberculosis. J Mycobac Dis. 2014;4:5.

2. Tzvetkov D, Tzvetkova P. Tuberculosis of male genital system myth or reality in $21^{\text {st }}$ century. Arch Androl. 2006;52:375-81.

PMid:16873138

3. Figueiredo AA, Lucon AM, Srougi M. Urogenital tuberculosis. Microbiol Spectr. 2017;5(1):1-15.

PMid:28087922

4. Drudi F, Laghi A, lannicelli E, Di Nardo R, Occhiato R, Poggi R, et al. Tubercular epididymitis and orchitis: US patterns. Eur 
Radiol 1997;7:1076-8.

5. Chattopadhyay A, Bhatnagar V, Agarwala S, Mitra DK Genitourinary tuberculosis in pediatric surgical practice. J Pediatr Surg. 1997;32(9):1283-6.

PMid:9314243

6. Lacambra C, Sollis-Villa J. Recurrent orchiepididymitis, 6 months after likely military tuberculosis. Arch Esp Urol. 1999;52:518-20. PMid:10427891

7. Walker D, Jordan P. Etiology of tuberculosis. J Urol. 1968;100:36-7.

8. Muttarak M, Peh WC, Lojanapiwat B, Chaiwun B. Tuberculous epididymitis and epididymo-orchitis: Sonographic appearances. AJR Am J Roentgenol. 2001;176(6):1459-66.

PMid:11373214

9. Borges WM, Bechara GR, Miranda MM, Figueiredo GB, Venturini BA, Laghi CR. Epididymis tuberculosis: Case report and brief review of the literature. Urol Case Rep. 2019;26:100969. PMid:31367526

10. Badmos KB. Tuberculous epididymo-orchitis mimicking a testicular tumour: Acase report. Afr Health Sci. 2012;12(3):395-7. PMid:23382759

11. Paul J, Krishnamoorthy S, Teresa M, Kumar S. Isolated tuberculous orchitis: A mimicker of testicular malignancy. Indian J Urol. 2010;26(2):284-6.

PMid:20877610
12. Wolf JS, McAninch JW. Tubercular epididymo-orchitis: Diagnosis by fine needle aspiration. J Urol. 1991;145(4):836-8. PMid:2005712

13. Chirindel A, Martinez F, Gagliardi JA, Armm MF. Testicular tuberculosis without epididymitis simulating neoplasm. Radiol Case Rep. 2008;3(3):133. PMid:27303531

14. Muttarak M, Peh W. Case 91: Tuberculous epididymo-orchitis. Radiology. 2006;238:748-51. PMid:16436828

15. Tessler FN, Tublin ME, Rifkin MD. US case of the day Tuberculous epididymoorchitis. Radiographics. 1998;18:251-3. PMid:9460131

16. Madeb R, Marshall J, Nativ O, Ertuk E. Epididimal tuberculosis: Case report and review of literature. Urology. 2005;65(4):798. PMid:15833542

17. Figueiredo AA, Lucon AM, Arvellos NA, Ramos CO, Toledo $A C$, Falci $R$ Jr., et al. A better understanding of urogenital tuberculosis pathophysiology based on radiological findings. Eur J Radiol. 2010;76(2):246-57. PMid:19556089

18. Kumar P, Shashikala P, Chandrashekar HR, Alva NK. Acquired immunodeficiency syndrome presenting as testicular tuberculosis. J Assoc Physicians India. 2000;48:1111-2. PMid:11310394 